\title{
miR-182 controls cell growth in gastrointestinal stromal tumors by negatively regulating CYLD expression
}

\author{
TIANLONG LING* ${ }^{*}$ FENGRONG YU* and HUI CAO \\ Department of Gastrointestinal Surgery, Renji Hospital, School of Medicine, \\ Shanghai Jiao Tong University, Shanghai 200120, P.R. China
}

Received February 22, 2018; Accepted September 4, 2018

DOI: 10.3892/or.2018.6765

\begin{abstract}
Gastrointestinal stromal tumors (GISTs) are the most common type of mesenchymal tumor of the digestive tract. MicroRNAs (miRNAs) are short non-coding RNAs, which control gene expression at a post-transcriptional level. Dysregulated miRNAs are involved in various types of human disease, including cancer. In the present study, it was revealed that miRNA-182 (miR-182) expression was significantly upregulated in human GISTs compared with adjacent normal tissues. Overexpression of miR-182 enhanced GIST-T1 cell growth, with increased proliferation and decreased apoptosis. miR-182 upregulation also promoted colony formation and migration of GIST-T1 cells. In addition, cylindromatosis (CYLD) was identified as a direct target of miR-182. Overexpression of miR-182 suppressed CYLD expression and enhanced downstream nuclear factor $(\mathrm{NF})-\kappa \mathrm{B}$ activation. It was also determined that the expression of CYLD was downregulated in association with upregulated miR-182 in human GISTs. In conclusion, these results demonstrated that miR-182 promoted GIST cell growth by negatively regulating CYLD expression. These findings indicated that miR-182 antagonist may be a promising therapeutic strategy for the treatment of human GIST.
\end{abstract}

\section{Introduction}

Gastrointestinal stromal tumors (GISTs) are the most common type of mesenchymal tumor of the digestive tract. According to worldwide reports, $60-70 \%$ of GISTs are detected in the stomach, and $25-35 \%$ are found in the small or large intestine. Only a small percentage of GISTs occur in other parts of the gastrointestinal tract (1). For early-stage or locally advanced

Correspondence to: Dr Hui Cao, Department of Gastrointestinal Surgery, Renji Hospital, School of Medicine, Shanghai Jiao Tong University, 160 Pujian Road, Shanghai 200120, P.R. China

E-mail: huicaorenji@aliyun.com

*Contributed equally

Key words: miR-182, GIST, CYLD, microRNA drug, cancer
GISTs, surgery is the optimal treatment method. However, the prognosis for patients with GISTs is usually poor, as GISTs have limited responses to traditional treatments such as radiotherapy and chemotherapy $(2,3)$.

Recent studies have identified oncogenic kinase mutations in GISTs. The subsequent introduction of kinase inhibitors as potential antineoplastic has provided a new insight into the treatment of GISTs (4). The KIT (also known as CD117) and platelet derived growth factor receptor $\alpha$ (PDGFRA) genes, which encode 2 type III receptor tyrosine kinases are recognized as the 2 most common mutations in GISTs $(5,6)$. Though progress has been made, the pathogenesis of GISTs is not fully understood and there may be other genetic regulators of the disease.

MicroRNAs (miRNA) are a type of hairpin-derived small non-coding RNA, which can regulate gene expression at a posttranscriptional level. More than $60 \%$ of protein-coding genes have been computationally predicted as miRNA targets, based on evolutionarily conserved base-pairing between mRNAs and the seed sequences of miRNAs (7). It is evident that miRNAs play essential roles in the regulation of multiple cellular processes, including proliferation (8), apoptosis (9), differentiation (10) and the cell cycle (11). The abnormal expression of miRNAs contributes to the pathogenesis of multiple human diseases $(12)$, including cancer $(13,14)$. A growing body of studies has uncovered a number of significant roles of miRNAs in the development of human GISTs, including associations with tumorigenesis, tumor progression, prognosis and drug resistance (15-22). miR-221 and miR-222 induce GIST cell apoptosis by negatively regulating the KIT/protein kinase B (AKT) signaling pathway (18). miR-21 sensitizes GIST cells to imatinib treatment by supressing B-cell lymphoma 2 (BCL-2) expression (17). Recently, dysregulated miR-182 was observed in various types of malignant tumors (23-30). However, little is known about the role of miR-182 in human GISTs.

In the present study, it was found that miR-182 was aberrantly upregulated in human GISTs compared with adjacent normal tissues. Silencing of miR-182 via a miR-182 specific inhibitor, suppressed cell proliferation and enhanced apoptosis. In addition, miR-182 promoted GIST-T1 cell colony formation and migration. Furthermore, cylindromatosis (CYLD) was identified as a direct target of miR-182. The overexpression of miR-182 reduced CYLD expression, resulting in enhanced $\mathrm{NF}-\kappa \mathrm{B}$ activation. It was also revealed that the expression 
of CYLD significantly decreased in association with the upregulation of miR-182 in human GISTs.

\section{Materials and methods}

Human study subjects. The human GISTs and adjacent normal tissues used in the present study were obtained from Shanghai Renji Hospital after informed consent was obtained from the patients. The samples were immediately snap-frozen in liquid nitrogen. All samples were confirmed as GISTs by trained pathologists. The study was approved by the Ethics Committee of Renji Hospital, Shanghai Jiao Tong University (Shanghai, China).

Cell culture and transfection. The human GIST-T1 cell line was a gift from the Shanghai Cancer Institute. The GIST-T1 cell line is derived from a GIST from the stomach of a Japanese woman, and has adherent cell culture properties. The cells were cultured in Dulbecco's modified Eagle's medium (DMEM) supplemented with 10\% fetal bovine serum (FBS), penicillin $(100 \mathrm{U} / \mathrm{ml})$ and streptomycin $(100 \mu \mathrm{g} / \mathrm{ml})$ (all from Gibco; Thermo Fisher scientific, Inc., Waltham, MA, USA). Lipofectamine ${ }^{\circledR}$ RNAiMAX and 2000 transfection reagents (Invitrogen; Thermo Fisher Scientific, Inc.) were used for transfection, following the manufacturer's instructions. The miR-182 mimic and inhibitor, plus the corresponding negative controls (NCs) were purchased from GenePharma (Shanghai GenePharma Co., Ltd., Shanghai, China). A total of $100 \mathrm{nM}$ NC mimic or miR-182 mimic and $200 \mathrm{nM} \mathrm{NC}$ inhibitor or miR-182 inhibitor were transfected.

Cell proliferation assay (CCK-8 assay). A total of $1 \times 10^{3}$ GIST-T1 cells were seeded in a 96-well plate and incubated at $37^{\circ} \mathrm{C}$ until the cells reached $30-40 \%$ confluence. Then, the cells were transfected with miR-182 mimic, inhibitor or the corresponding NCs. Cell proliferation was assessed at 24, 48 and $72 \mathrm{~h}$ as follows: $10 \mu \mathrm{l} \mathrm{CCK-8} \mathrm{solution} \mathrm{(Dojindo} \mathrm{Molecular}$ Technologies, Inc., Kumamoto, Japan) was added to each well and after $2 \mathrm{~h}$ of incubation at $37^{\circ} \mathrm{C}$, the optical density (OD) at $450 \mathrm{~nm}$ was read by a microplate spectrophotometer. Four independent experiments were conducted.

Apoptosis assay. Annexin V-staining was performed using an Annexin V-FITC apoptosis detection kit (BD Biosciences, Franklin Lakes, NJ, USA) according to the manufacturer's instructions. Briefly, after incubation the cells were harvested, washed with phosphate-buffered saline (PBS) and stained with Annexin V-FITC and propidium iodide in a binding buffer for $15 \mathrm{~min}$ at $37^{\circ} \mathrm{C}$ in the dark. The samples were then analyzed by flow cytometry using a FACScan flow cytometer.

Colony formation assay (CFA). After transfection with the miR-182 mimic, inhibitor or corresponding NCs, a total of 500 cells were plated in a 6 -well plate in complete culture medium. After 10-14 days, when the colonies were visible to the naked eye, the cell culture was terminated by removal of the medium and the cells were washed with PBS. The colonies were fixed with methanol for $15 \mathrm{~min}$, and then dried and stained with Giemsa solution for $10 \mathrm{~min}$. Images of the stained plates were captured using a Nikon camera and the numbers of colonies containing $>50$ cells were counted using densitometric software (Clono-Counter). Each treatment was performed in triplicate.

Cell migration assay. The ability of cells to migrate was determined using a modified 24-well Boyden chamber (8- $\mu \mathrm{m}$ pore size; Corning Costar, Cambridge, MA, USA). GIST-T1 cells were seeded in the upper chamber of a Transwell at a density of 1 x 105 cells in $100 \mu 1$ DMEM without FBS, while DMEM with $10 \%$ FBS was added into the lower chamber. After incubation for $24 \mathrm{~h}$ at $37^{\circ} \mathrm{C}$, the cells that had migrated to the lower surface of the filter were fixed with methanol for $10 \mathrm{~min}$ and stained with crystal violet for $15 \mathrm{~min}$. The membrane was then washed with distilled water for 4 times. Five random microscopic fields of each well were selected and migrated cells were counted using a Leica DMIL LED inverted microscope (magnification, x100). The mean number of cells per field was recorded.

Reverse transcription-quantitative polymerase chain reaction $(R T-q P C R)$. Total RNA was extracted using TRIzol reagent (Invitrogen; Thermo Fisher Scientific, Inc.). The expression of miR-182 was quantified using a TaqMan miRNA assay kit (Thermo Fisher Scientific, Inc.). U6, a small nuclear RNA, was used as the internal control. To determine the gene expression levels, RNA was converted to cDNA using the PrimeScript RT Reagent kit (Takara Bio, Inc., Otsu, Japan). RT-qPCR was then performed using a SYBR Premix Ex Taq RT-PCR kit (Takara Bio, Inc.). GAPDH was used as the internal control. The sequences of the PCR primers used were as follows: GAPDH forward, 5'-GTCTCCTCTGACTTCAACAGCG-3' and reverse, 5'-ACCACCCTGTTGCTGTAGCCAA-3'; human Ki-67 forward, 5'-GAAAGAGTGGCAACCTGCCTTC-3' and reverse, 5'-GCA CCAAGTTTTACTACATCTGCC-3'; human p65 forward, 5'-TGAACCGAAACTCTGGCAGCTG-3' and reverse, 5'-TGAACCGAAACTCTGGCAGCTG-3'; human CYLD forward, 5'-GGTAATCCGTTGGATCGGTCAG-3' and reverse 5'-AGTGCCTCTGAAGGTTCCATCC-3' The thermocycling conditions were as follows: Denatured at $95^{\circ} \mathrm{C}$ for $15 \mathrm{sec}$, followed by 40 cycles with denaturation at $95^{\circ} \mathrm{C}$ for $5 \mathrm{sec}$ and annealing at $60^{\circ} \mathrm{C}$ for $30 \mathrm{sec}$.

Western blotting. GIST-T1 cells were lysed by a radio immunoprecipitation buffer containing proteinase and panphosphatase inhibitors (Thermo Fisher Scientific, Inc.). The protein concentration was determined by BCA quantification. A total of $30 \mu \mathrm{g}$ of proteins were loaded and separated by $10 \%$ SDS-PAGE gel. The gel was then transferred to polyvinylidene difluoride (PVDF) membranes at $180 \mathrm{~mA}$ for $2 \mathrm{~h}$. The membranes were incubated with blocking buffer (TBS containing 5\% BSA and 0.1\% Tween-20) at room temperature for $1 \mathrm{~h}$. Primary antibodies of phosphorylated (Ser) p65 (dilution 1:1,000; cat. no. 3033; Cell Signaling Technology, Inc., Danvers, MA, USA), p65 (dilution 1:1,000; cat. no. 8242; Cell Signaling Technology, Inc.), $\beta$-tubulin (dilution 1:1,000; cat. no. 5666; Cell Signaling Technology, Inc.) and CYLD (dilution 1:1,000; cat. no. 8462; Cell Signaling Technology, Inc.) were incubated at $4^{\circ} \mathrm{C}$ overnight. The membranes were detected by Pierce ECL Western Blotting Substrate (Thermo Fisher Scientific, Inc.). Tanon 4100 Gel Imaging Analysis System 
Table I. Clinicopathological information of human GIST patients.

\begin{tabular}{|c|c|c|c|c|c|c|}
\hline Patient ID & Sex & Age (yrs.) & Size $\left(\mathrm{cm}^{3}\right)$ & Location & Mitotic index & Risk $^{\mathrm{a}}$ \\
\hline Patient 1 & Male & 57 & 269.5 & Stomach & $<5 / 50 \mathrm{HPF}^{\mathrm{b}}$ & Medium \\
\hline Patient 2 & Female & 59 & 1050.0 & Retroperitoneum & $<5 / 50 \mathrm{HPF}$ & High \\
\hline Patient 3 & Male & 80 & 1190.0 & Stomach & $>10 / 50 \mathrm{HPF}$ & High \\
\hline Patient 4 & Male & 66 & 18.0 & Stomach & $>10 / 50 \mathrm{HPF}$ & High \\
\hline Patient 5 & Female & 62 & 1000.0 & Stomach & $>10 / 50 \mathrm{HPF}$ & High \\
\hline Patient 6 & Female & 74 & 1152.0 & Stomach & $>10 / 50 \mathrm{HPF}$ & High \\
\hline Patient 7 & Female & 52 & 270.0 & Stomach & $<5 / 50 \mathrm{HPF}$ & Medium \\
\hline Patient 8 & Male & 52 & 283.5 & Stomach & 5-10/50 HPF & Medium \\
\hline Patient 9 & Male & 72 & 45.0 & Stomach & $5-10 / 50 \mathrm{HP}$ & Medium \\
\hline Patient 10 & Female & 75 & 90.0 & Stomach & 5-10/50 HPF & Medium \\
\hline Patient 11 & Female & 62 & 384.0 & Stomach & 5-10/50 HPF & High \\
\hline Patient 12 & Male & 48 & 82.5 & Duodenum & $<5 / 50 \mathrm{HPF}$ & Medium \\
\hline Patient 13 & Female & 53 & 1680.0 & Stomach & $>10 / 50 \mathrm{HPF}$ & High \\
\hline Patient 14 & Male & 69 & 60.0 & Stomach & $>5 / 50 \mathrm{HPF}$ & Medium \\
\hline Patient 15 & Female & 56 & 15.0 & Stomach & $<5 / 50 \mathrm{HPF}$ & Low \\
\hline Patient 16 & Female & 62 & 130.0 & Small intestine & $\leq 5 / 50 \mathrm{HPF}$ & Medium \\
\hline Patient 17 & Male & 86 & 1584.0 & Stomach & $>10 / 50 \mathrm{HPF}$ & High \\
\hline Patient 18 & Male & 39 & 1072.5 & Stomach & $<5 / 50 \mathrm{HPF}$ & High \\
\hline Patient 19 & Male & 65 & 2.5 & Stomach & $<5 / 50 \mathrm{HPF}$ & Low \\
\hline Patient 20 & Female & 53 & 2.0 & Small intestine & $<2 / 50 \mathrm{HPF}$ & Low \\
\hline
\end{tabular}

${ }^{a}$ The GIST risk was classified according to the modified NIH 2008 version. The related variables included tumor size, mitotic index, location, presence of intraoperative tumor rupture and metastasis; ${ }^{b} \mathrm{HPF}$, high power field. GIST, gastrointestinal stromal tumor.

(Tanon Science \& Technology Co., Ltd., Shanghai, China) was used for densitometry. All results were normalized against $\beta$-tubulin.

Luciferase reporter assay. The 3'-untranslated region (UTR) of CYLD that contains a predicted binding site of miR-182 validated by the web tool TargetScanHuman 7.2 was cloned into the psiCHECK-2 vector (Promega Corp., Madison, WI, USA). The primers used were as follows: forward, 5'-CCGCTCGAGATGTCATGTTCCTCACCTCC-3' and reverse, 5'-ATAAGAATGCGGCCGCCTGAT ACAATCCTAGGCACCT-3'. The GIST-T1 cells were cultured in a 96 -well plate to $80 \%$ confluence. They were then transfected with $20 \mathrm{ng}$ 3'-UTR luciferase reporter vector or the empty vector with miR-182 mimic, inhibitor or the corresponding NCs using Lipofectamine 2000, according to the manufacturer's instructions. After $24 \mathrm{~h}$ the cells were lysed and subjected to a luciferase reporter activity assay. The ratio of Renilla luciferase activity to firefly luciferase activity was calculated.

Statistical analysis. Three independent experiments were performed to confirm the reproducibility of each experiment in vitro. The data was presented as the mean \pm standard error of the mean. Differences between groups were analyzed for statistical significance using the Student's t-test and two-way analysis of variance followed by the Bonferroni post hoc test. The correlation between miR-182 and CYLD was investigated using Spearman correlation and linear regression. A
P-value $<0.05$ was deemed to indicate a statistically significant difference.

\section{Results}

miR-182 is ectopically expressed in human GISTs. To study the role of miR-182 in human GISTs, miR-182 expression was quantified using a TaqMan microRNA assay in a cohort of GIST patient samples. A total of 20 human GIST specimens and their corresponding adjacent normal tissues were analyzed (Table I). The results revealed that miR-182 was significantly upregulated in human GISTs compared with the adjacent normal tissues (Fig. 1A). In addition, the expression levels of miR-182 were strongly associated with the clinicopathological characteristics, including risk category, mitotic index and tumor size (Fig. 1B-D). It was also noted that the expression levels of $\mathrm{Ki}-67$, which is an indicator of abnormal cell proliferation, were significantly elevated in GISTs compared with the adjacent normal tissues (Fig. 1E).

miR-182 enhances GIST cell proliferation. To further investigate the role of miR-182 in GISTs, the effect of miR-182 on cell proliferation was evaluated by manipulating miR-182 expression in the GIST-T1 cell line. Overexpressing or silencing of miR-182 was performed by transfection of the synthesized miR-182 mimic or inhibitor, respectively. The corresponding non-specific oligonucleotides were used as NCs. As shown by q-PCR, the expression levels of miR-182 were significantly increased in the miR-182 mimic-transfected group compared 
A

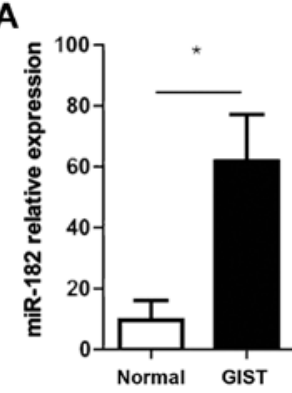

B

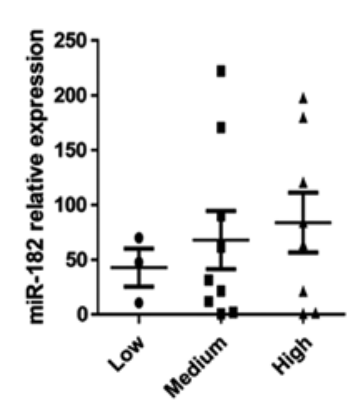

C

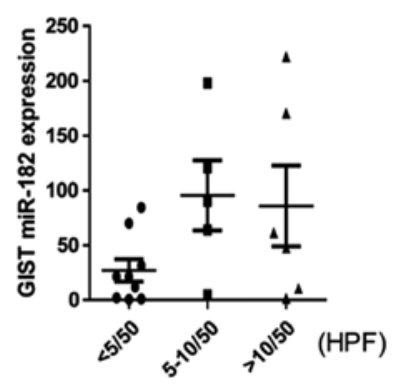

D

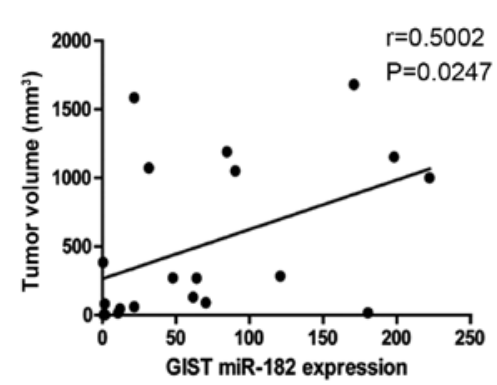

E

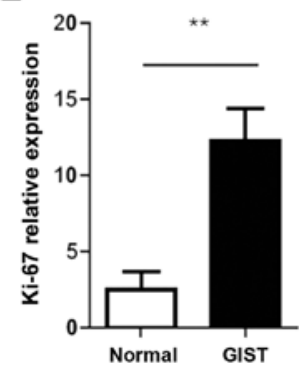

Figure 1. miR-182 is ectopically expressed in human GISTs. (A) miR-182 expression in GIST and tumor-adjacent normal tissue. (B-D) The association of miR-182 expression with the clinicopathological characteristics, including risk category, mitotic index and tumor size. (E) Ki-67 expression in GIST and normal tissues. Bars represent the means \pm SEM. ${ }^{* *} \mathrm{P}<0.01$. GISTs, gastrointestinal stromal tumors.

A

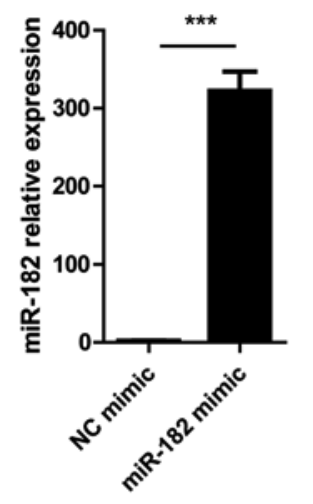

C
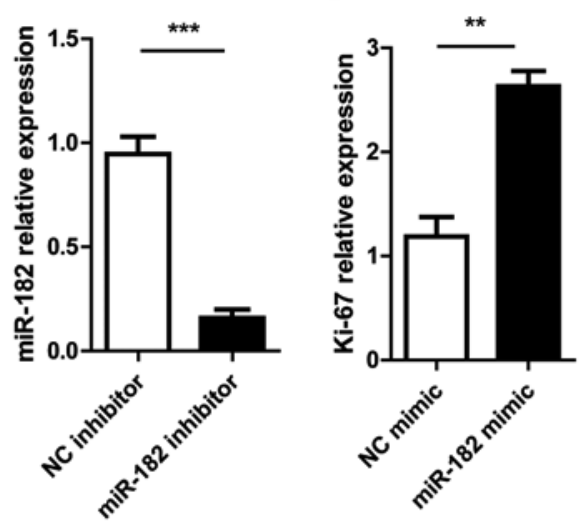

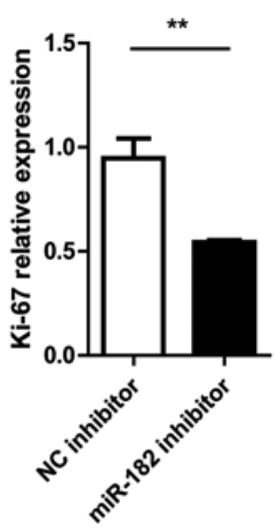

B
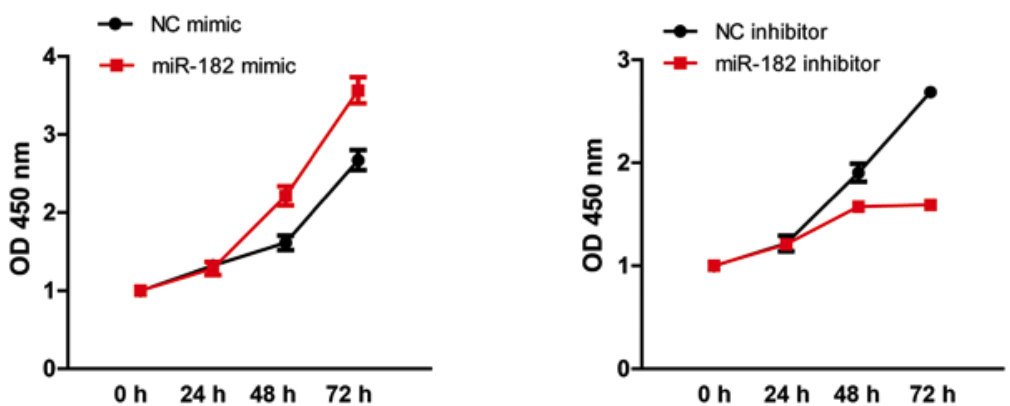

Figure 2. miR-182 enhances GIST-T1 cell proliferation. (A) The expression levels of miR-182 in GIST-T1 cells with miR-182 mimic or inhibitor transfection. (B) The proliferation ability of GIST-T1 cells transfected with miR-182 mimics or inhibitors was analyzed by a CCK-8 assay. (C) mRNA levels of Ki-67 in GIST-T1 cells transfected with miR-182 mimics or inhibitors. Bars represent the means \pm SEM. ${ }^{* *} \mathrm{P}<0.01,{ }^{* * *} \mathrm{P}<0.001$. The data are representative of 3 independent experiments. GIST, gastrointestinal stromal tumor.

with the NC mimic group. In the miR-182 inhibitor group, miR-182 expression was 5 -fold lower compared with the inhibitor NC group (Fig. 2A). It was found that miR-182 overexpression significantly upregulated Ki-67 expression. The 
A

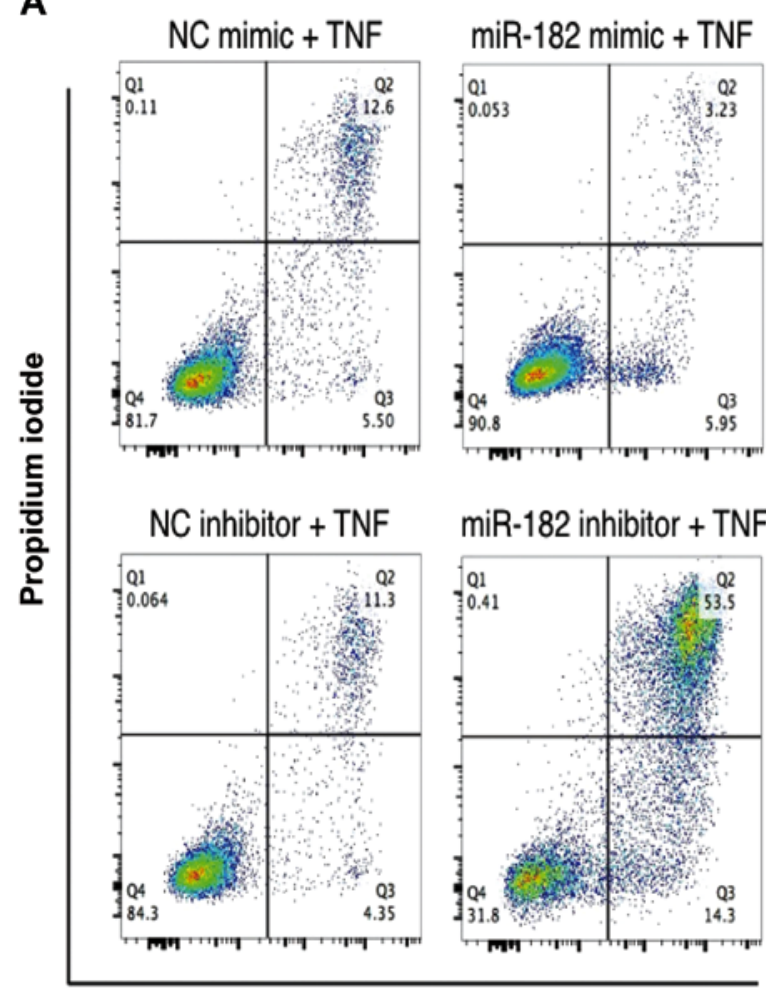

B
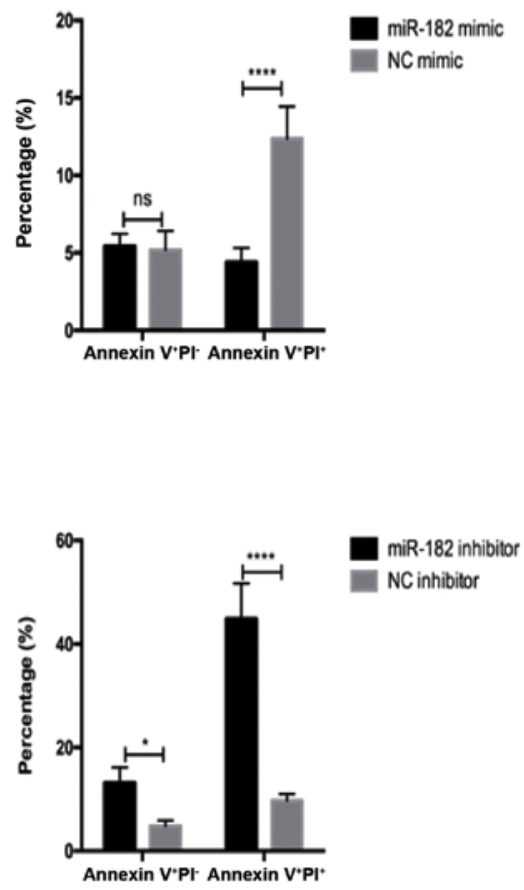

Annexin V-FITC

Figure 3. miR-182 inhibits TNF $\alpha$-induced GIST-T1 cell apoptosis. (A) After transfection with miR-182 mimics, inhibitors or corresponding NCs, GIST-T1 cells were incubated with $20 \mathrm{ng} / \mathrm{ml} \mathrm{TNF} \alpha$ for $24 \mathrm{~h}$ and subsequently stained with Annexin V-FITC and propidium iodide, followed by analysis using a flow cytometer. Early apoptotic cells (Annexin $\mathrm{V}^{+}$and $\left.\mathrm{PI}^{-}\right)$were displayed in the lower right quadrant and late apoptotic cells $\left(\mathrm{Annexin} \mathrm{V}^{+}\right.$and $\left.\mathrm{PI}^{+}\right)$are shown in the upper right quadrant. (B) The number of apoptotic cells was quantified. Bars represent the means $\pm \mathrm{SD}$. ${ }^{*} \mathrm{P}<0.05$, ${ }^{* * * * *} \mathrm{P}<0.0001$. The data are representative of 3 independent experiments. GIST, gastrointestinal stromal tumor.

pro-proliferative function of the miR-182 mimic was further verified by a CCK- 8 assay. Transfection with the miR-182 inhibitor suppressed cell growth and decreased Ki-67 expression (Fig. 2B and C).

miR-182 inhibits GIST cell apoptosis. It was then investigated whether miR-182 influenced GIST cell apoptosis. Flow cytometric analysis was performed to analyze PI and Annexin V staining of GIST-T1 cells treated with TNF $\alpha$ for $24 \mathrm{~h}$. It was determined that overexpression of miR-182 did not affect early apoptosis, as revealed by Annexin $\mathrm{V}^{+} \mathrm{PI}^{-}$, however it did significantly suppress late apoptosis (Annexin $\mathrm{V}^{+} \mathrm{PI}^{+}$) (Fig. 3A). Conversely, inhibition of miR-182 promoted both early and late apoptosis (Fig. 3B).

miR-182 stimulates colony formation and migration of GIST cells. The role of miR-182 in GIST-T1 cell growth and migration was evaluated by performing a CFA and Transwell migration assay, respectively. The results of the CFA revealed that GIST-T1 cells transfected with miR-182 mimic exhibited a higher colony formation rate compared with the mimic NC group (Fig. 4A). Conversely, the miR-182 inhibitor suppressed colony formation (Fig. 4B). In the Transwell migration assay, overexpression of miR-182 enhanced GIST-T1 cell migration and silencing of miR-182 blocked cell migration (Fig. 4C and D), which indicated that miR-182 could promote tumor cell migration.
$C Y L D$ is a direct target of miR-182. CYLD is recognized as a tumor suppressor, which is involved in various types of carcinoma, including breast and lung cancer (31-34). It was observed that the expression of CYLD was downregulated in association with the upregulation of miR-182 in human GISTs compared with adjacent normal tissues (Fig. 5A and B). Sequence alignment revealed that the 3'-UTR of CYLD mRNA contains a binding site for the miR-182 seed region (Fig. 5C). It is known that miRNA regulates gene expression by base-pairing its target mRNAs with the seeding region, which leads to mRNA degradation or translation repression (35). To further explore whether CYLD is a target of miR-182, a luciferase reporter assay was performed. The reporter plasmid psiCHECK2 contained the 3'UTR of CYLD and was co-transfected with the miR-182 mimic, inhibitor or corresponding NC into GIST-T1 cells. The luciferase assay revealed that miR-182 regulated luciferase activity in a CYLD 3'-UTR dependent manner (Fig. 5D). Collectively, these results demonstrated that CYLD is a direct target of miR-182.

miR-182 enhances $N F-\kappa B$ signaling by negatively regulating $C Y L D$. A number of previous studies have revealed that CYLD promotes cell survival and oncogenesis by negatively regulating $\mathrm{NF}-\kappa \mathrm{B}$ signaling $(32,36)$. Steady state $\mathrm{NF}-\kappa \mathrm{B}$ is sequestered by $\mathrm{I}-\kappa \mathrm{B}$ in the cytoplasm. However, upon activation $I-\kappa B$ is phosphorylated and undergoes degradation. The released $N F-\kappa B$ dimer (p50-p65) is then phosphorylated 

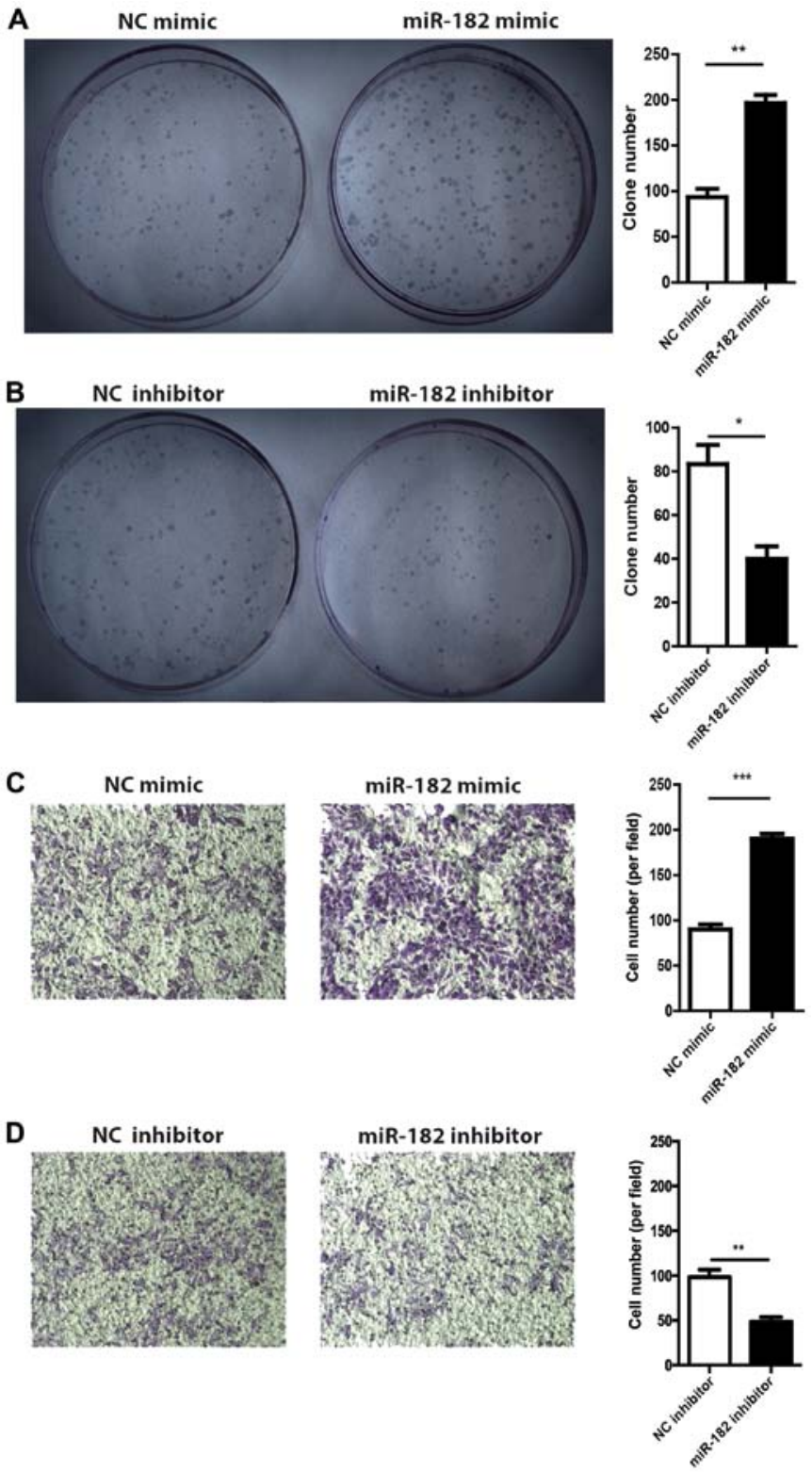

Figure 4. miR-182 promotes GIST-T1 cell colony formation and migration. (A and B) Representative images and quantification of NC mimic or miR-182 mimic, NC inhibitor or miR-182 inhibitor-transfected GIST-T1 cells as analyzed by a colony formation assay. (C and D) Representative images and quantification of migrated cells analyzed using a Transwell assay. Bars represent the means \pm SEM. ${ }^{*} \mathrm{P}<0.05,{ }^{* *} \mathrm{P}<0.01,{ }^{* * *} \mathrm{P}<0.001$. The data are representative of 3 independent experiments. GIST, gastrointestinal stromal tumor.

and translocates into the nucleus where it binds with the cognate response elements, inducing gene transcription (37). Therefore, the phosphorylation of p65 is recognized as an activation indicator of the $\mathrm{NF}-\kappa \mathrm{B}$ signaling pathway. It was revealed that the expression levels of p65 were significantly increased in human GISTs compared with the adjacent normal tissues (Fig. 6A). Overexpression of miR-182 in GIST-T1 cells significantly upregulated p65 expression, while inhibition of miR-182 downregulated its expression (Fig. 6B). To further investigate the role of miR-182 in the regulation of $\mathrm{NF}-\kappa \mathrm{B}$ signaling, $\mathrm{TNF} \alpha$-induced $\mathrm{NF}-\kappa \mathrm{B}$ activation was investigated in GIST-T1 cells with miR-182 intervention. GIST-T1 cells transfected with miR-182 mimics exhibited reduced protein expression of CYLD and enhanced NF- $\mathrm{NB}$ activation, as determined by 65 phosphorylation, compared with the mimic NC group. Conversely, silencing miR-182 reduced p65 phosphorylation and increased CYLD expression (Fig. 6C). These results demonstrated that miR-182 promoted $\mathrm{NF}-\kappa \mathrm{B}$ signaling by negatively regulating CYLD expression.

\section{Discussion}

Recently, a number of studies have demonstrated that miRNAs are involved in human malignancies by regulating multiple genes associated with various aspects of cancer biology $(38,39)$. Characterization of cancer-specific miRNAs as well as their functional targets and target-mediated signaling pathways, would improve understanding of miRNAs in tumorigenesis, which may be important for the identification of novel therapeutic targets $(40,41)$. In the present study, it was determined that miR-182 was ectopically expressed in human GISTs compared with the adjacent normal tissues. miR-182 was originally thought to be specifically expressed in sensory organs (42). However, recent studies have revealed the oncogenic role of miR-182 in various types of human cancer (43-51). Aberrant expression of miR-182 enhanced melanoma metastasis by negatively regulating FOXO3 and microphthalmia-associated transcription factor expression (26). In the present study, it was observed that silencing miR-182 significantly inhibited GIST-T1 cell growth and invasion, which indicated that miR-182 may be developed into a therapeutic treatment option for human GISTs. However, further in vivo animal experiments are required to ascertain this.

CYLD is a deubiquitinase, which can cleave lysine 63 -linked ubiquitin chains from the target protein (31). It was originally identified as a gene which was mutated in familial cylindromatosis, which predisposes patients to skin cylindroma $(52,53)$. Recent studies have revealed that CYLD has a significant suppressive role in cell survival and proliferation. The loss of CYLD expression has been observed in various types of human cancer $(54,55)$. In the present study, it was revealed that the expression of CYLD was significantly decreased in human GISTs, and was associated with the upregulation of miR-182. A luciferase reporter assay revealed that CYLD is a direct target of miR-182. Inhibition of miR-182 enhanced CYLD expression in GIST-T1 cells, which resulted in reduced cell proliferation and increased cell apoptosis.

$\mathrm{NF}-\kappa \mathrm{B}$ comprises a family of 5 transcription factors, which can form distinct hetero- or homo-dimers and control responsive gene expression (56). Rigid regulation of $\mathrm{NF}-\kappa \mathrm{B}$ signaling is vital for various cellular bioprocesses (57). Aberrant activation of $\mathrm{NF}-\kappa \mathrm{B}$ is observed in multiple types of human cancer where it promotes tumor cell survival through stimulation of anti-apoptotic gene expression (58-61). The results in the present study revealed that $\mathrm{NF}-\kappa \mathrm{B}$ was upregulated in human GISTs compared with adjacent normal tissues. CYLD is known to be a dominant negative regulator of NF- $\kappa \mathrm{B}$ signaling. GIST cells with increased CYLD protein levels exhibited reduced p65 phosphorylation in response to $\mathrm{TNF} \alpha$ stimulation. Therefore, the present study uncovered a regulatory axis of miR-182/CYLD/NF- $\mathrm{BB}$ which mediated cell survival in GISTs. 
A

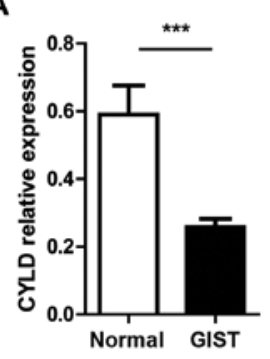

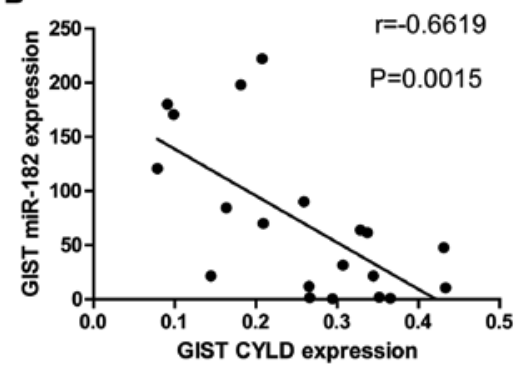

C

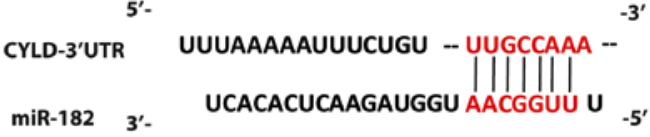

D
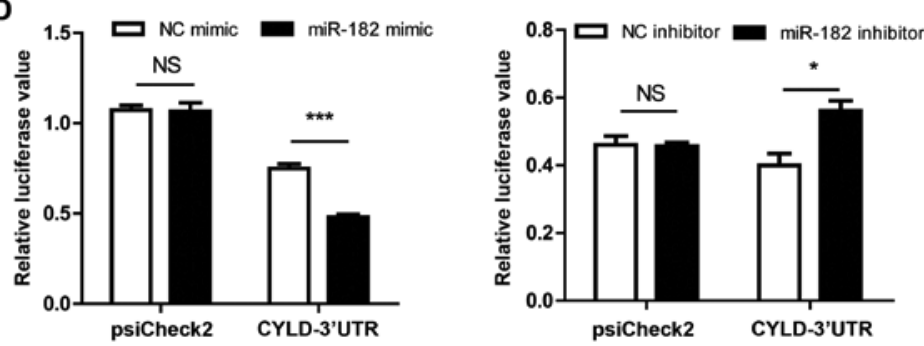

Figure 5. CYLD is a direct target of miR-182. (A) The expression of $C Y L D$ mRNA was downregulated in tissue samples from GIST patients compared with normal samples. (B) Tumor tissue miR-182 was negatively correlated with CYLD levels in GIST patients. (C) Predicted binding sites for miR-182 in the 3'-UTR of CYLD. (D) GIST-T1 cells were transfected with the control construct (psiCHECK-2), or a construct encoding the wild-type $C Y L D$ 3'-UTR in addition to the miR-182 mimic (left) or miR-182 inhibitor (right). After $24 \mathrm{~h}$ the luciferase activity in GIST-T1 cells lysates was detected. Bars represent the mean \pm SEM. ${ }^{*} \mathrm{P}<0.05,{ }^{* * * *} \mathrm{P}<0.001$. The data are representative of 3 independent experiments. CYLD, cylindromatosis; GIST, gastrointestinal stromal tumor.

A

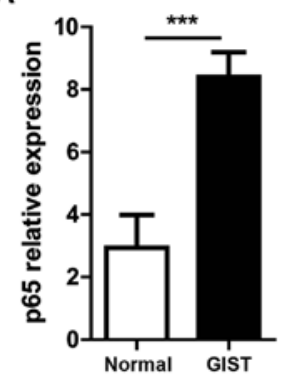

C

$\begin{array}{lllllll}\mathrm{TNF} \alpha(\min ) & 0 & 15 & 30 & 0 & 15 & 30 \\ \mathrm{NC} \text { mimic } & + & + & + & - & - & - \\ \text { miR-182 mimic } & - & - & - & + & + & +\end{array}$

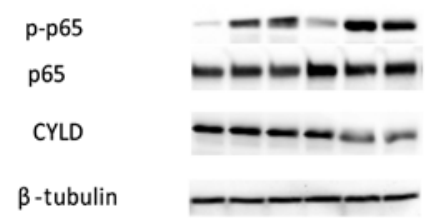

B
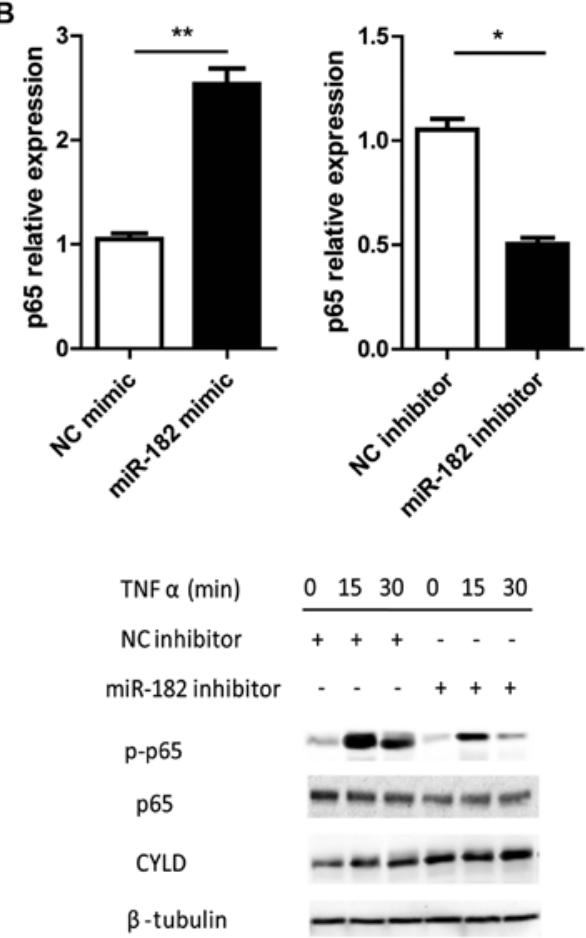

Figure 6. miR-182 enhances NF-kB activation by negatively regulating CYLD. (A) Expression levels of $p 65$ in human GIST and adjacent normal tissues. (B) After transfection with miR-182 mimic or inhibitor the GIST-T1 cells were incubated with $20 \mathrm{ng} / \mathrm{ml}$ TNF $\alpha$ for $24 \mathrm{~h}$. Changes in the level of $p 65 \mathrm{mRNA}$ were analyzed by quantitative polymerase chain reaction. (C) GIST-T1 cells were transfected with NC, miR-182 mimic or inhibitor. After $24 \mathrm{~h}$ the cells were stimulated with TNF $\alpha$. p65, phosphorylated (Ser) p65 and CYLD were analyzed by western blotting. $\beta$-tubulin was used to confirm equal protein loading. Bars represent the mean \pm SEM. ${ }^{*} \mathrm{P}<0.05,{ }^{* *} \mathrm{P}<0.01,{ }^{* * *} \mathrm{P}<0.001$. The data are representative of 3 independent experiments. CYLD, cylindromatosis; GIST, gastrointestinal stromal tumor. 
Reduction of apoptosis is a typical hallmark of tumor progression, and one mechanism by which miRNAs influence cancer development is through the mediation of the apoptotic signaling pathway (62-65). In the present study, it was revealed that miR-182 was involved in regulating GIST cell apoptosis. Overexpression of miR-182 reduced TNF $\alpha$ induced late apoptosis, as determined by Annexin V and PI double-positive staining. However, it had little effect on early apoptosis (Annexin $\mathrm{V}^{+} \mathrm{PI}^{-}$) in the miR-182 mimic-treated cells. This is not the first time that miRNA has selectively affected the late-stage apoptosis of cancer cells. A previous study by Wang et al demonstrated that miRNA-196b promoted pancreatic cancer cell growth by inhibiting late apoptosis via negative regulation of CADM1 expression (66). Further studies are required to investigate the molecular mechanism of how miR-182 mediates late apoptosis in GIST cells.

In conclusion, the results of the present study demonstrated that miR-182 was aberrantly expressed in human GISTs. It was also revealed that miR-182 promoted GIST cell growth and invasion. In addition, tumor suppressor CYLD was identified as a direct target of miR-182. These findings indicated that miR-182 functions as an oncomiR in GIST and may represent a promising therapeutic target for human GIST treatment.

\section{Acknowledgements}

Not applicable.

\section{Funding}

The present study was supported by grants from the Shanghai Hospital Development Center (grant no. 16CR3001A) and the State Key Laboratory of Oncogenes and Related Genes (grant no. 90-15-01)

\section{Availability of data and materials}

The datasets used during the present study are available from the corresponding author upon reasonable request.

\section{Authors' contributions}

HC conceived and designed the study. TL and FY performed the experiments and analyzed the data. TL wrote the manuscript. FY and HC reviewed and edited the manuscript. All authors read and approved the manuscript and agree to be accountable for all aspects of the research in ensuring that the accuracy or integrity of any part of the work are appropriately investigated and resolved.

\section{Ethics approval and consent to participate}

The study was approved by the Ethics Committee of Renji Hospital, Shanghai Jiao Tong University (Shanghai, China) and informed consent was obtained from all patients.

\section{Patient consent for publication}

Not applicable.

\section{Competing interests}

The authors declare that they have no conflicting financial interests.

\section{References}

1. Miettinen M, Sobin LH and Lasota J: Gastrointestinal stromal tumors of the stomach: A clinicopathologic, immunohistochemical, and molecular genetic study of 1765 cases with long-term follow-up. Am J Surg Pathol 29: 52-68, 2005.

2. Huang RX, Xiang $P$ and Huang C: Gastrointestinal stromal tumors: Current translational research and management modalities. Eur Rev Med Pharmacol Sci 18: 3076-3085, 2014.

3. Dematteo RP, Heinrich MC, El-Rifai WM and Demetri G: Clinical management of gastrointestinal stromal tumors: Before and after STI-571. Hum Pathol 33: 466-477, 2002.

4. Corless CL, Barnett CM and Heinrich MC: Gastrointestinal stromal tumours: Origin and molecular oncology. Nat Rev Cancer 11: 865-878, 2011.

5. Hirota S, Isozaki K, Moriyama Y, Hashimoto K, Nishida T, Ishiguro S, Kawano K, Hanada M, Kurata A, Takeda M, et al: Gain-of-function mutations of c-kit in human gastrointestinal stromal tumors. Science 279: 577-580, 1998.

6. Heinrich MC, Corless CL, Duensing A, McGreevey L, Chen CJ, Joseph N, Singer S, Griffith DJ, Haley A, Town A, et al: PDGFRA activating mutations in gastrointestinal stromal tumors. Science 299: 708-710, 2003.

7. Friedman RC, Farh KK, Burge CB and Bartel DP: Most mammalian mRNAs are conserved targets of microRNAs. Genome Res 19: 92-105, 2009.

8. Lenkala D, LaCroix B, Gamazon ER, Geeleher P, Im HK and Huang RS: The impact of microRNA expression on cellular proliferation. Hum Genet 133: 931-938, 2014.

9. Hwang HW and Mendell JT: MicroRNAs in cell proliferation, cell death, and tumorigenesis. Br J Cancer 96 (Suppl): R40-R44, 2007.

10. Shivdasani RA: MicroRNAs: regulators of gene expression and cell differentiation. Blood. 108: 3646-3653, 2006.

11. Bueno MJ and Malumbres M: MicroRNAs and the cell cycle. Biochim Biophys Acta 1812: 592-601, 2011.

12. Tüfekci KU, Oner MG, Meuwissen RL and Genç S: The role of microRNAs in human diseases. Methods Mol Biol 1107: 33-50, 2014.

13. Hayes J, Peruzzi PP and Lawler S: MicroRNAs in cancer: Biomarkers, functions and therapy. Trends Mol Med 20: 460-469, 2014.

14. Reddy KB: MicroRNA (miRNA) in cancer. Cancer Cell Int 15: $38,2015$.

15. Kim WK, Yang HK and Kim H: MicroRNA involvement in gastrointestinal stromal tumor tumorigenesis. Curr Pharm Des 1227-1235, 2013.

16. Fan R, Zhong J, Zheng S, Wang Z, Xu Y, Li S, Zhou J and Yuan F: MicroRNA-218 inhibits gastrointestinal stromal tumor cell and invasion by targeting KIT. Tumour Biol 35: 4209-4217, 2014.

17. Cao CL, Niu HJ, Kang SP, Cong CL and Kang SR: miRNA-21 sensitizes gastrointestinal stromal tumors (GISTs) cells to Imatinib via targeting B-cell lymphoma 2 (Bcl-2). Eur Rev Med Pharmacol Sci 20: 3574-3581, 2016.

18. Ihle MA, Trautmann M, Kuenstlinger H, Huss S, Heydt C, Fassunke J, Wardelmann E, Bauer S, Schildhaus HU, Buettner R, et al: miRNA-221 and miRNA-222 induce apoptosis via the KIT/ AKT signalling pathway in gastrointestinal stromal tumours. Mol Oncol 9: 1421-1433, 2015.

19. Kim WK, Park M, Kim YK, Tae YK, Yang HK, Lee JM and Kim H: MicroRNA-494 downregulates KIT and inhibits gastrointestinal stromal tumor cell proliferation. Clin Cancer Res 17: 7584-7594, 2011.

20. Akçakaya P, Caramuta S, Åhlen J, Ghaderi M, Berglund E, Östman A, Bränström R, Larsson C and Lui WO: microRNA expression signatures of gastrointestinal stromal tumours: Associations with imatinib resistance and patient outcome. Br J Cancer 111: 2091-2102, 2014.

21. Akçakaya P and Lui WO: MicroRNAs and gastrointestinal stromal tumor. Adv Exp Med Biol 889: 51-70, 2015. 
22. Haller F, von Heydebreck A, Zhang JD, Gunawan B, Langer C, Ramadori G, Wiemann S and Sahin O: Localization- and mutation-dependent microRNA (miRNA) expression signatures in gastrointestinal stromal tumours (GISTs), with a cluster of co-expressed miRNAs located at 14q32.31. J Pathol 220: 71-86, 2010.

23. Chiang $\mathrm{CH}$, Hou MF and Hung WC: Up-regulation of miR-182 by $\beta$-catenin in breast cancer increases tumorigenicity and invasiveness by targeting the matrix metalloproteinase inhibitor RECK. Biochim Biophys Acta 1830: 3067-3076, 2013.

24. Tang T, Wong HK, Gu W, Yu MY, To KF, Wang CC, Wong YF, Cheung TH, Chung TK and Choy KW: MicroRNA-182 plays an onco-miRNA role in cervical cancer. Gynecol Oncol 129 199-208, 2013

25. Guttilla IK and White BA: Coordinate regulation of FOXO1 by miR-27a, miR-96, and miR-182 in breast cancer cells. J Biol Chem 284: 23204-23216, 2009.

26. Segura MF, Hanniford D, Menendez S, Reavie L, Zou X, Alvarez-Diaz S, Zakrzewski J, Blochin E, Rose A, Bogunovic D, et al: Aberrant miR-182 expression promotes melanoma metastasis by repressing FOXO3 and microphthalmia-associated transcription factor. Proc Natl Acad Sci USA 106: 1814-1819, 2009.

27. Liu Z, Liu J, Segura MF, Shao C, Lee P, Gong Y, Hernando E and Wei JJ: MiR-182 overexpression in tumourigenesis of high-grade serous ovarian carcinoma. J Pathol 228: 204-215, 2012.

28. Moskwa P, Buffa FM, Pan Y, Panchakshari R, Gottipati P, Muschel RJ, Beech J, Kulshrestha R, Abdelmohsen K, Weinstock DM, et al: miR-182-mediated downregulation of BRCA1 impacts DNA repair and sensitivity to PARP inhibitors. Mol Cell 41: 210-220, 2011

29. Jiang L, Mao P, Song L, Wu J, Huang J, Lin C, Yuan J, Qu L, Cheng SY and Li J: miR-182 as a prognostic marker for glioma progression and patient survival. Am J Pathol 177: 29-38, 2010.

30. Song L, Liu L, Wu Z, Li Y, Ying Z, Lin C, Wu J, Hu B, Cheng SY, Li M, et al: TGF- $\beta$ induces miR-182 to sustain NF- $\kappa$ B activation in glioma subsets. J Clin Invest 122: 3563-3578, 2012.

31. Massoumi R: CYLD: A deubiquitination enzyme with multiple roles in cancer. Future Oncol 7: 285-297, 2011.

32. Sun SC: CYLD: A tumor suppressor deubiquitinase regulating NF-kappaB activation and diverse biological processes. Cell Death Differ 17: 25-34, 2010

33. Hayashi M, Jono H, Shinriki S, Nakamura T, Guo J, Sueta A, Tomiguchi M, Fujiwara S, Yamamoto-Ibusuki M, Murakami K, et al: Clinical significance of CYLD downregulation in breast cancer. Breast Cancer Res Treat 143: 447-457, 2014.

34. Deng LL, Shao YX, Lv HF, Deng HB and Lv FZ: Over-expressing CYLD augments antitumor activity of TRAIL by inhibiting the $\mathrm{NF}-\kappa \mathrm{B}$ survival signaling in lung cancer cells. Neoplasma 59: $18-29,2012$.

35. Lewis BP, Burge CB and Bartel DP: Conserved seed pairing, often flanked by adenosines, indicates that thousands of human genes are microRNA targets. Cell 120: 15-20, 2005.

36. Courtois G: Tumor suppressor CYLD: Negative regulation of NF-kappaB signaling and more. Cell Mol Life Sci 65: 1123-1132, 2008.

37. Oeckinghaus A and Ghosh S: The NF-kappaB family of transcription factors and its regulation. Cold Spring Harb Perspect Biol 1: a000034, 2009.

38. Calin GA and Croce CM: MicroRNA-cancer connection: The beginning of a new tale. Cancer Res 66: 7390-7394, 2006.

39. Farazi TA, Hoell JI, Morozov P and Tuschl T: MicroRNAs in human cancer. Adv Exp Med Biol 774: 1-20, 2013

40. Cheng CJ and Slack FJ: The duality of oncomiR addiction in the maintenance and treatment of cancer. Cancer J 18: 232-237, 2012.

41. Kasinski AL and Slack FJ: Epigenetics and genetics. MicroRNAs en route to the clinic: Progress in validating and targeting microRNAs for cancer therapy. Nat Rev Cancer 11: 849-864, 2011

42. Wei Q, Lei R and Hu G: Roles of miR-182 in sensory organ development and cancer. Thorac Cancer 6: 2-9, 2015.

43. Hanke M, Hoefig K, Merz H, Feller AC, Kausch I, Jocham D, Warnecke JM and Sczakiel G: A robust methodology to study urine microRNA as tumor marker: microRNA-126 and microRNA-182 are related to urinary bladder cancer. Urol Oncol 28: 655-661, 2010

44. Wang J, Li J, Shen J, Wang C, Yang L and Zhang X: MicroRNA-182 downregulates metastasis suppressor 1 and contributes to metastasis of hepatocellular carcinoma. BMC Cancer 12: 227, 2012.
45. Hirata H, Ueno K, Shahryari V, Deng G, Tanaka Y, Tabatabai ZL Hinoda Y and Dahiya R: MicroRNA-182-5p promotes cell invasion and proliferation by down regulating FOXF2, RECK and MTSS1 genes in human prostate cancer. PLoS One 8: e55502, 2013.

46. Lei R, Tang J, Zhuang X, Deng R, Li G, Yu J, Liang Y, Xiao J, Wang HY, Yang Q, et al: Suppression of MIM by microRNA-182 activates RhoA and promotes breast cancer metastasis. Oncogene 33: 1287-1296, 2014.

47. Yan D, Dong XD, Chen X, Yao S, Wang L, Wang J, Wang C, $\mathrm{Hu} \mathrm{DN}, \mathrm{Qu} \mathrm{J}$ and Tu L: Role of microRNA-182 in posterior uveal melanoma: Regulation of tumor development through MITF, BCL2 and cyclin D2. PLoS One 7: e40967, 2012.

48. Yang WB, Chen PH, Hsu T, Fu TF, Su WC, Liaw H, Chang WC and Hung JJ: Sp1-mediated microRNA-182 expression regulates lung cancer progression. Oncotarget 5: 740-753, 2014.

49. Rasheed SA, Teo CR, Beillard EJ, Voorhoeve PM and Casey PJ: MicroRNA-182 and microRNA-200a control G-protein subunit $\alpha-13$ (GNA13) expression and cell invasion synergistically in prostate cancer cells. J Biol Chem 288: 7986-7995, 2013.

50. Yang MH, Yu J, Jiang DM, Li WL, Wang S and Ding YQ: microRNA-182 targets special AT-rich sequence-binding protein 2 to promote colorectal cancer proliferation and metastasis. J Transl Med 12: 109, 2014.

51. Wang YQ, Guo RD, Guo RM, Sheng W and Yin LR: MicroRNA-182 promotes cell growth, invasion, and chemoresistance by targeting programmed cell death 4 (PDCD4) in human ovarian carcinomas. J Cell Biochem 114: 1464-1473, 2013.

52. Bowen S, Gill M, Lee DA, Fisher G, Geronemus RG, Vazquez ME and Celebi JT: Mutations in the CYLD gene in Brooke-Spiegler syndrome, familial cylindromatosis, and multiple familial trichoepithelioma: Lack of genotype-phenotype correlation. J Invest Dermatol 124: 919-920, 2005.

53. Bignell GR, Warren W, Seal S, Takahashi M, Rapley E, Barfoot R, Green H, Brown C, Biggs PJ, Lakhani SR, et al: Identification of the familial cylindromatosis tumour-suppressor gene. Nat Genet 25: $160-165,2000$.

54. Nikolaou K, Tsagaratou A, Eftychi C, Kollias G, Mosialos G and Talianidis I: Inactivation of the deubiquitinase CYLD in hepatocytes causes apoptosis, inflammation, fibrosis, and cancer. Cancer Cell 21: 738-750, 2012.

55. Hellerbrand C, Bumes E, Bataille F, Dietmaier W, Massoumi R and Bosserhoff AK: Reduced expression of CYLD in human colon and hepatocellular carcinomas. Carcinogenesis 28: 21-27, 2007.

56. Gilmore TD: Introduction to NF-kappaB: Players, pathways, perspectives. Oncogene 25: 6680-6684, 2006.

57. Schreck R, Albermann K and Baeuerle PA: Nuclear factor kappa B: An oxidative stress-responsive transcription factor of eukaryotic cells (a review). Free Radic Res Commun 17: 221-237, 1992.

58. Wang CY, Mayo MW and Baldwin AS Jr: TNF- and cancer therapy-induced apoptosis: Potentiation by inhibition of NF-kappaB. Science 274: 784-787, 1996.

59. Dolcet X, Llobet D, Pallares J and Matias-Guiu X: NF- $\kappa B$ in development and progression of human cancer. Virchows Arch 446: 475-482, 2005.

60. Xia Y, Shen S and Verma IM: NF- $\kappa$ B, an active player in human cancers. Cancer Immunol Res 2: 823-830, 2014.

61. Karin M, Cao Y, Greten FR and Li ZW: NF-kappaB in cancer: From innocent bystander to major culprit. Nat Rev Cancer 2: 301-310, 2002.

62. Jovanovic $M$ and Hengartner MO: miRNAs and apoptosis: RNAs to die for. Oncogene 25: 6176-6187, 2006.

63. Lima RT, Busacca S, Almeida GM, Gaudino G, Fennell DA and Vasconcelos $\mathrm{MH}$ : MicroRNA regulation of core apoptosis pathways in cancer. Eur J Cancer 47: 163-174, 2011.

64. Pileczki V, Cojocneanu-Petric R, Maralani M, Neagoe IB and Sandulescu R: MicroRNAs as regulators of apoptosis mechanisms in cancer. Clujul Med 89: 50-55, 2016.

65. Subramanian S and Steer CJ: MicroRNAs as gatekeepers of apoptosis. J Cell Physiol 223: 289-298, 2010.

66. Wang HL, Zhou R, Liu J, Chang Y, Liu S, Wang XB, Huang MF and Zhao Q: MicroRNA-196b inhibits late apoptosis of pancreatic cancer cells by targeting CADM1. Sci Rep 7: 11467, 2017. 